\title{
Below Replacement Fertility, Net International Migration and Canada's Future Population
}

\author{
S. Mitra \\ Emory University \\ Atlanta, Georgia, USA \\ and \\ Statistics Canada \\ Ottawa, Ontario, Canada
}

\section{Abstract}

The indefinite continuation of Canada's below replacement fertility and emigration as well as the current policy of admitting a fixed number of immigrants every year, will eventually result in a stationary population. The size and composition of that population will be determined by the same aspects of the immigrant population and its eventual adoption of the host country's reproductive norm. The characteristics of this population may differ from the conventional stationary population in several respects. Among others, the birth rate will be less than the death rate, and, in Canada's case, the ultimate age structure may not be monotonically declining but may show more than one modal age.

\section{Résumé}

Le maintien indéfini du taux de fécondité sous le niveau de remplacement, l'émigration et les politiques actuelles du Canada autorisant un nombre limité d'immigrants chaque année se traduiront éventuellement par une population stationnaire - đont le nombre et la composition seront déterminés par ceux de la population immigrante et par le fait qu'elle adoptera éventuellement la norme reproductive du pays hôte. Les caractéristiques de cette population seront peut-être différentes de celles de la population stationnaire conventionnelle par plusieurs aspects. Entre autres, le taux de natalité sera inférieur au taux de mortalité et, dans le cas du Canada, l'ultime structure par âge ne déclinera peut-être pas đe façon monotonique mais pourrait montrer plus d'un âge modal.

Key Words: stationary population, native-born population, constant size and age composition of immigrants, constant emigration rate at all ages

\section{The Problem}

The roles of immigration and emigration, in determining the pattern of growth and the changing composition of a population are becoming increasingly important in Canada. This is because the declining trend of Canada's fertility, which is now holding at a level well below replacement, is showing no sign of reversing itself. The consequences of such a state of affairs have been studied at some length by several agencies of the Government of Canada and have been reported by Basavarajappa and George (1981), Employment and Immigration Canada (1983), and Basavarajappa, Verma and Picton (1984). The impact of different levels of net international migration, coupled with alternative levels of vital rates, has been analyzed in these works in terms of varying trends of population sizes and their age composition. 


\section{S. Mitra}

Determination of the long term effects of a fixed schedule of mortality and fertility rates and specific patterns of emigration and immigration on key population variables can, however, be made from the traditional stable population model with appropriate modifications. Such modifications are necessary since the theory of the stable population model, as originally formulated, is based on the assumption that the population is closed to migration while fertility and mortality specific for age remain constant at all times. The relaxation of the assumption of the absence of population movement is a significant advancement in the application of the stable population model (Espenshade et al., 1982; Mitra, 1983; Mitra and Cerone, 1986). It has been found that the procedure for projecting population in the presence of migration can be made amenable to appropriate mathematical modeling, the usefulness of which extends far beyond that of conventional methods. Similar models can also be used to determine how the composition of the population by linguistic, ethnic or other categories may change over time.

Specifically, it has been shown (Espenshade, et al., 1982; Mitra, 1983) that when (a) fertility is below replacement, (b) a constant number of immigrants with unchanging age distribution enters the country every year and (c) there is no emigration, the population eventually becomes stationary as the immigrants and/or their descendants adopt the maternity rates of the host country. The ultimate size of that population is determined, among other things, by the size and age distribution of the immigrants and the net reproduction rate of the host country.

If the host population's fertility happens to be exactly at the level of replacement, the limiting form of the trajectory of births will turn out to be a straight line with a positive slope. When the fertility is above replacement, the trajectory can be shown to increase exponentially. It can similarly be shown that in the presence of emigration, appropriate conclusions could be reached mathematically when the age composition of the net migrants remains invariant over time or when the emigration rate remains constant at all ages and the size and the age composition of the immigrants remain fixed at all times.

These ideas are also useful in formulating ways of studying the time differentials in the growth curves of the subgroups of a population experiencing their respective net maternity rates. At any given time, these groups may have fertility rates above, at or below replacement levels. Then, the composition of the immigrants measured in terms of their distribution in the subgroups can be shown as one of the major 
determinants of their ultimate size. These and other similar examples demonstrate the utility and the potentials of mathematical models in the field of population projection.

As is well known, the stable model can provide both the trajectory of births beginning at the start of the process and thereafter, the age composition of the population which in a way is similar to the projection of a population by the method of components. However, the major advantage of the model, especially when fertility is at the below replacement level, lies in its ability to provide the limiting size and composition of the population and also the time by which the population will approximate that state.

What follows next is the derivation of some of the results that are interesting in this context. For the sake of simplicity, zero or a constant emigration rate at all ages shall be assumed - the effect of which, in the latter case, can be measured in terms of a reduction of the net reproduction rate (see appendix). Further, as is customary with the stable population model, this study will deal only with the female population.

\section{Size of the Immigrant Population}

Let $I(x)$ be the number of immigrants aged $x$ entering the country at any time. Then the total number of immigrants aged $x, t$ years after the start of the process will be given by

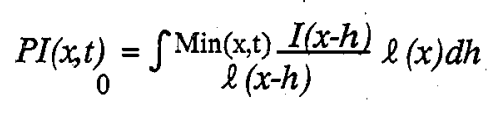

where like $I(x)$, the probability $\ell(x)$ of surviving from birth to age $x$, has also been assumed constant at all times. Observe that (1) does not change in the interval $t \geq x$, within which its constant value is given by

$$
P I(x)=\ell(x) \int_{0}^{x} \frac{I(x-h)}{\ell(x-h)} d h
$$

This is so because both $I(x)$ and $\ell(x)$ are defined only for $x \geq 0$.

The characteristics of the age composition of the immigrants as it reaches its limiting form when $t$ exceeds the span of life $\alpha$, may be quite different from that of an ordinary age distribution. This may be seen by assuming a simple structure of $I(x)$ such as

$$
I(x)=k \ell(x)
$$


where $k$ is a constant. That is to say, the size of the immigrant population entering at any time is proportional to that of its stationary population at all ages. According to the conditions of the present model, the substitution of (3) in (2) then gives the limiting size of the immigrant population as

$$
P I(x)=k x x(x)
$$

Note the unusual nature of the age distribution given by (4), which is bellshaped for Canada's life table (see Figure 1), such that the size of the population increases from zero at age zero until it reaches a maximum at some age say $\hat{x}$ and declines thereafter to become zero again at $x=\alpha$. The model age $\hat{x}$ can be obtained by differentiating (4) with respect to and equating it to zero. That gives

$$
\hat{x}=\frac{1}{\mu(\hat{x})}
$$

where the function $\mu(x)$ stands for the force of mortality at age $x$ given by

$$
\mu(x)=-\frac{1}{\ell(x)} \frac{d \ell(x)}{d x}
$$

For the 1981 Canadian female life table, the age which is equal to the reciprocal of the force of mortality at that age happens to be 67 . Note that this result is obtained from our model based on the assumption that $I(x)$ is proportional to $\ell(x)$. However, the same results derived from the actual age distribution of the recent immigrants is not as different as that of the model value. In fact, for the 1985 age distribution of the immigrants, that model age turns out to be 65 (see Figure 1).

The two curves show how for the same $I$, the limiting values of $P I(x)$ based on the actual and the model values of $I(x)$ can differ from one another.

For the model age distribution of immigrants the total number entering at any time $t$ can be obtained from (3) as

$$
I=\int_{0}^{\alpha} k \ell(x) d x=k e(0)
$$

and the limiting size of the immigrant population from (4) as

$$
P I=\int_{0}^{\alpha} k x \ell(x) d x=k e(0) m=I m
$$


where $e(0)$ is the life expectancy and $m$ is the average age of the stationary population. Observe that the ultimate size of the immigrant population is reached $\alpha$ years after the start of the process, which means that the immigrant population also becomes stationary in the sense that it stops changing from that point in time. Intuitively, we can suggest that the

FIGURE 1. AGE DISTRIBUTION OF THE ULTIMATE POPULATION OF IMMIGRANTS (FEMALES) IN CANADA ASSUMING CURRENT LEVELS OF MORTALITY AND FERTILITY AND THE GIVEN AND THE MODEL AGE COMPOSITION OF 30,000 ANNUAL IMMIGRANTS

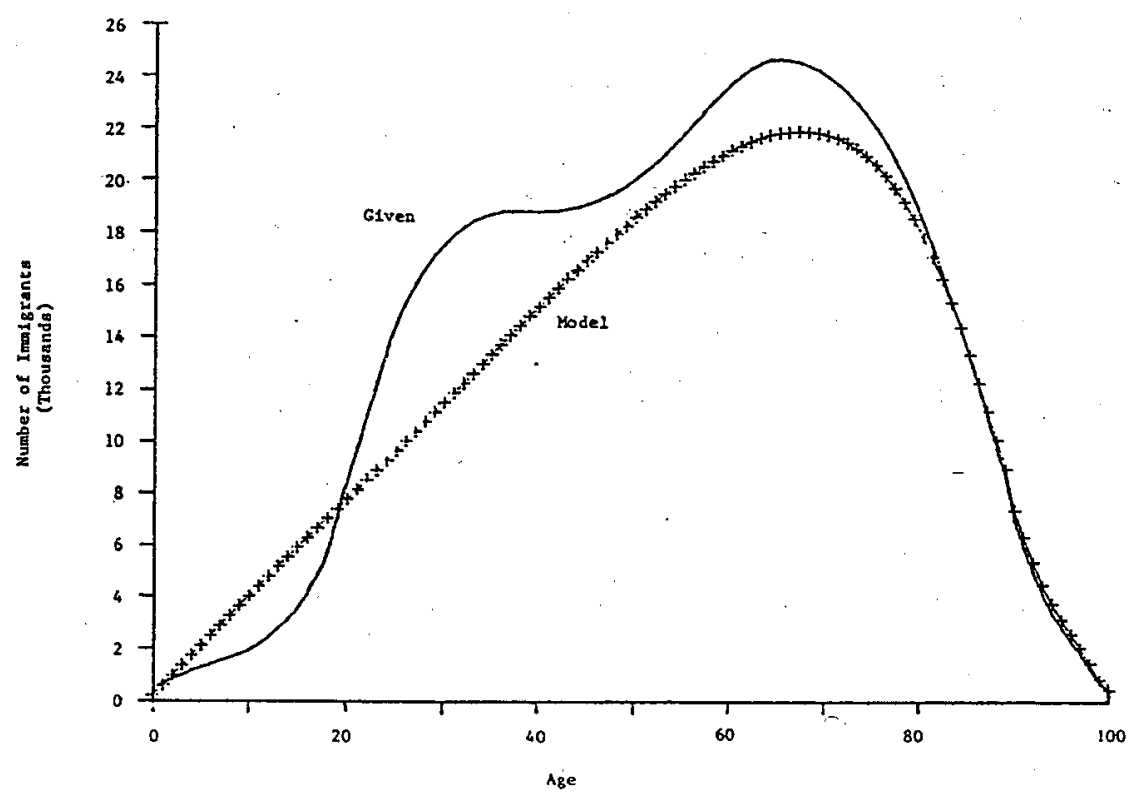

decline in this population (regardless of its composition) due to deaths by, say, $D(I)$ must be matched only by the number of new entrants. That is to say,

$$
D(I)=I
$$

Note that births to immigrants do not count since the children of immigrants are not immigrants themselves but are native-born and should be recorded accordingly. Formal proof of (9) is provided in the next section. 


\section{S. Mitra}

Deaths Among Immigrants

The number of deaths $D(I)$ among the immigrants can be expressed as

$$
D I=\int_{0}^{\alpha} P I(x) \mu(x) d x
$$

Substitution of (2) for $P I(x)$ in (10) gives

$$
D I=\int_{0}^{\alpha} \ell(x) \mu(x) \int_{0}^{x} \frac{I(x-h)}{\ell(x-h)} d h d x
$$

Writing

$$
F(x)=\int_{0}^{x} \frac{I(x-h)}{\ell(x-h)} d h
$$

Equation (10) can be written as

$$
D(I)=-\int_{0}^{\alpha} F(x) \frac{d \ell(x)}{d x} d x
$$

Noting from (11) that

$$
F(x)=\frac{I(x)}{\ell(x)}
$$

we can carry on the integration of (12) by parts to get

$$
\mathrm{D}(\mathrm{I})=-\mathrm{F}(\mathrm{x}) \ell(\mathrm{x})]_{0}^{\alpha}+\int_{0}^{\alpha} \ell(x) F(x) d x=\underset{0}{0}+\int^{\alpha} I(x) d x=I
$$

due to (14) and since by definition $F(0)=0$. Observe that the proof of the equality relationship in (15) or (9) does not depend on any specific pattern of the distribution of $I(x)$ like the one given by (3).

\section{Limiting Value of the Number of Births to the Immigrants}

The number of births to the immigrants must assume its limiting value $B(I)$ as soon as the age composition becomes stationary in the reproductive interval. The number of years it will take to happen after the start of the process should be equal to the upper boundary of the reproductive interval, which is approximately 50 years. At that time, we can express the limiting value of the number of births to the immigrants as 
Below Replacement Fertility, Net International Migration and Canada's Future Population

$$
\mathrm{B}(\mathrm{I})=\int_{0}^{\alpha} P I(x) m(x) d x
$$

where $m(x)$ is the age-specific fertility rate at age $x$. Even though this calculation has used the same mortality and fertility rates for both the native-born population and the immigrant population, it is not an absolute requirement; the author has done so for the sake of notational simplicity. If, in fact, the rates are indeed different for the two groups, one would then compute $B(I)$ by using the appropriate rates.

When the age composition of the immigrants is similar to that of the proposed model (equation 4), (16) can be simplified as

$$
B(I)=k \int_{0}^{\alpha} x \ell(x) m(x) d x=k R T
$$

where the net reproduction rate is

$$
R=\int_{0}^{\alpha} \ell(x) m(x) d x
$$

and

$$
\mathrm{T}=\frac{\int_{0}^{\alpha} x \ell(x) m(x) d x}{R}
$$

is the average age of motherhood.

Limiting Values of the Number of Births and Deaths to the Native-Born Population

When $R<1$, it has been shown (Espenshade et al., 1982; Mitra, 1983) that the sum total of the number of births to the native-born populations and the immigrants attains the limiting value

$$
\dot{B}=\frac{B(I)}{l-R}
$$

This formula will hold even if $B(I)$ is based on net maternity rates different from those of the host population. The native-born component $B(N)$ of $B$ may then be written as

$$
B(N)=B-B(I)=\frac{B(I) R}{1-R}=B R
$$


due to (20). We also note that all the $B$ babies are native-born and therefore the limiting size of the native-born population aged $x$ is

$$
P N(x)=B \ell(x)
$$

and that of the total native-born population is

$$
P N=B \int_{0}^{\alpha} \ell(x) d x=B e(0)
$$

Therefore, the number of deaths among the native-born population can be obtained as

$$
D N=\int_{0}^{\alpha} P N(x) \mu(x) d x=\mathrm{B} \int_{0}^{\alpha} \ell(x) \mu(x) d x=B
$$

Thus the number of deaths $D(N)$ among the native-born population, exceeds the number of births $B(N)$ to them by

$$
D(N)-B(N)=B-B(N)=B(I)
$$

which then is a measure of the amount by which the native-born population falls short of reproducing itself. Thus, the children of the immigrants make up for this deficit and maintain the stationary nature of the native-born population. In short, it can be said that the two components $P N$ and $P I$ of the total population $P$ are both stationary in different ways. The first, or $P(N)$, needs the contribution of the second, or $P(I)$, towards the total number of births, and $P(I)$ needs continuous replenishment by the constant flow of immigrants $I$.

\section{Limiting Age Composition of the Total Population}

It has already been observed (see Figure 1) that the age composition of the immigrants is not like that of a conventional stationary population. Now one can also see that immigrants may account for a significant proportion of the total population when $R$ is considerably smaller than one. This is so because a rough estimate of the proportion can be obtained from their relative contribution to the total number of births or from

$$
\frac{B(I)}{B}=1-R
$$

That is to say, when the limit is reached, approximately $20 \%$ of the population will be immigrants if $R=0.8$. 
If the pattern of immigration follows the model age distribution given by (4), then one can obtain the proportion of the immigrants $P I$ to the total population $P$, as

$$
\frac{P I}{P}=\frac{P I}{P I+P N}=\frac{k e(0) m}{k e(0) m+B e(0)}
$$

due to (8) and (23). Substitution of (20) for $B$ and (17) for $B(\mathrm{I})$ simplifies (27) to

$$
\frac{P I}{P}=1+\frac{1}{\frac{R}{1-R} \frac{T}{m}}
$$

which for Canada's $R=0.8, T=27$ and $m=41$ turns out to be about $28 \%$. The proportion of immigrants derived from the observed age composition of the recent immigrants is about $24 \%$.

FIGURE 2. AGE DISTRIBUTION OF THE UNTIMATE STATIONARY POPULATION OF CANADA BASED ON THE CURRENT LEVELS OF MORTALITY, FERTILITY, AN EMIGRATION RATE OF .003 AND THE GIVEN AND THE MODEL AGE COMPOSITION OF 20,000 ANNUAL IMMIGRATION.

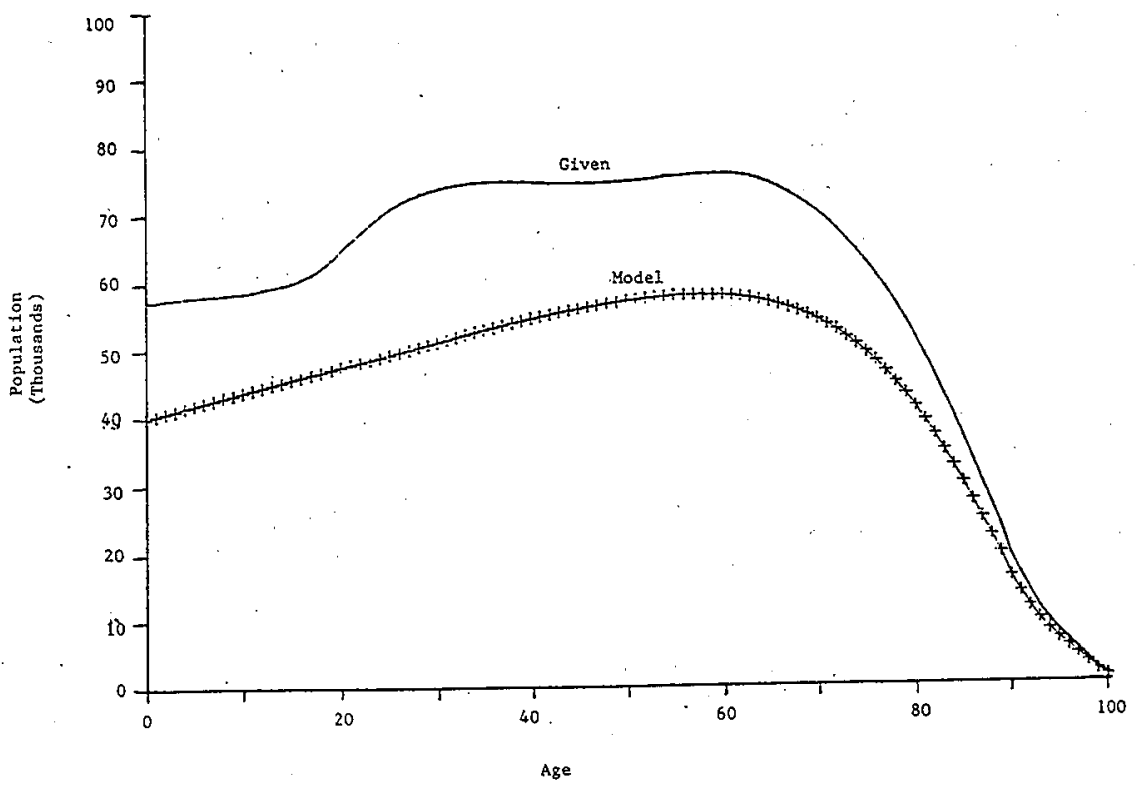




\section{S. Mitra}

It was observed earlier that the age composition of the native-born population given by (22) is stationary in the conventional sense, that is to say, the size of the population is a monotonic non-increasing function of age. The same for the immigrant population, although stationary, shows a maximum after age 60 for the model as well as for the actual distributions. Since the immigrants will account for a large proportion of the total population, similar abnormalities will be found in the limiting age distribution of the latter, as well (see Figure 2). Again, the differences between the two figures are due to the same between the model and the observed age composition of the immigrants.

\section{Limiting Values of the Birth and Death Rates}

The birth and death rates $b(N)$ and $d(N)$ of the native-born population can be derived directly from the analytical expressions of their respective components. Thus,

$$
b(N)=\frac{B(N)}{P(N)}=\frac{B R}{B e(0)}=\frac{R}{e(0)}
$$

due to (21) and (23). Similarly,

$$
d(N)=\frac{D(N)}{P(N)}=\frac{B}{B e(0)}=\frac{1}{e(0)}
$$

Thus for $R=0.8$ and $e(0)=80$ for Canada, the birth rate and death rate turn out to be 10 and 12.5 , respectively, per thousand population. Note that the age composition of the immigrants certainly affect their own rates, but not those of the native-born population. Thus for the model,

$$
b(I)=\frac{B(I)}{P I}=\frac{R T}{e(0) m}
$$

due to (17) and (8) and

$$
d(I)=\frac{D(I)}{P I}=\frac{I}{I m}=\frac{I}{m}
$$

due to (15) or (9) and (8). For the parametric values of Canada, the birth rate of the immigrant population works out as 6.6 and the death rate as 24.2. The same rates generated by the actual age distribution are 8.4 and 21.7, respectively. Compared to the model age distribution of the immigrants, the observed distribution is somewhat younger (Figure 1) resulting in a higher birth rate and a lower death rate. In comparison with 
either of these, the age distribution of the native-born population is much younger and that is why its birth rate is even higher and the death rate even lower. For the total population, the corresponding sets of these rates reflect the previously noted special features of the age distributions of the immigrants.

\section{Some Results}

All of the above-mentioned demographic characteristics of the limiting stationary populations and several others may be seen in Table 1.

TABLE 1. DEMOGRAPHIC CHARACTERISTICS ASSUMING VARYING AGE COMPOSITION OF THE IMMIGRANTS WITH MEASURES OF MORTALITY, FERTILITY AND IMMIGRATION

\begin{tabular}{|c|c|c|c|}
\hline \multicolumn{2}{|l|}{$\begin{array}{l}\text { Life Expectancy at Birth } \\
\text { Total Fertility Rate } \\
\text { Net Reproduction Rate } \\
\text { Average Age of Stationary Population } \\
\text { Average Age of Motherhood } \\
\text { Annual Number of Immigrants }\end{array}$} & $\begin{array}{c}\mathrm{e}(\mathrm{O}) \\
\mathrm{TFR} \\
\mathrm{R} \\
\mathrm{m} \\
\mathrm{T} \\
\mathrm{I}\end{array}$ & $\begin{array}{c}79.69 \\
1.66 \\
0.7923 \\
41.30 \\
27.41 \\
30000\end{array}$ \\
\hline \multirow[b]{2}{*}{ Parameters } & & \multicolumn{2}{|c|}{$\begin{array}{l}\text { Values of Parameters Based on } \\
\text { Age Distribution of Immigrants }\end{array}$} \\
\hline & & As Observed & $\begin{array}{l}\text { Proportional } \\
\text { to Stationary } \\
\text { Population }\end{array}$ \\
\hline Total Immigrant Population & $P(I)$ & 1384134 & 1239033 \\
\hline Average Age of Immigrants & $X(I)$ & 55.42 & 56.36 \\
\hline Births to Immigrants & $\mathrm{B}(\mathrm{I})$ & 11667 & 8177 \\
\hline Total Births & $B=B(I) /(1-R)$ & 56172 & 39369 \\
\hline Births to Natives & $B(N)=B-B(I)$ & 44505 & 31192 \\
\hline Deaths to Immigrants & $D(I)=I$ & 30000 & 30000 \\
\hline Deaths to Natives & $D(N)=B$ & 56172 & 39369 \\
\hline Total Deaths & $D=B+I$ & 86172 & 69369 \\
\hline Native Population & $\mathrm{P}(\mathrm{N})=\mathrm{Be}(\mathrm{O})$ & 4476328 & 3137290 \\
\hline Total Population & $P=P(I)+P(N)$ & 5860462 & 4376324 \\
\hline Birth Rate of Immigrants & $\mathrm{b}(\mathrm{I})=\mathrm{B}(\mathrm{I}) / \mathrm{P}(\mathrm{I})$ & 0.0084 & 0.0066 \\
\hline Birth Rate of Natives & $b(N)=B(N) / P(N)$ & 0.0099 & 0.0099 \\
\hline Birth Rate of Total Population & $\mathrm{b}=\mathrm{B} / \mathrm{P}$ & 0.0096 & 0.0090 \\
\hline Death Rate of Immigrants & $\mathrm{d}(\mathrm{I})=\mathrm{B}(\mathrm{I}) / \mathrm{P}(\mathrm{I})$ & 0.0217 & 0.0242 \\
\hline Death Rate of Natives & $\mathrm{d}(\mathrm{N})=\mathrm{D}(\mathrm{N}) / \mathrm{P}(\mathrm{N})$ & 0.0125 & 0.0125 \\
\hline Death Rate of Total Population & $\mathrm{d}=\mathrm{D} / \mathrm{P}$ & 0.0147 & 0.0159 \\
\hline Rate of Growth of Immigrants & $r(I)=b(I)-d(I)$ & -0.0132 & -0.0176 \\
\hline Rate of Growth of Natives & $r(N)=b(N)-d(N)$ & -0.0026 & -0.0026 \\
\hline Rate of Growth of Total Population & $r(P)=b-d$ & -0.0051 & -0.0069 \\
\hline Immigration Rate & $\mathrm{i}=\mathrm{I} / \mathrm{P}$ & 0.0051 & 0.0069 \\
\hline
\end{tabular}


The table is based on an annual number of 30,000 female immigrants. It may be mentioned that the averages, rates and ratios discussed earlier are independent of the actual volume of immigration, as those are determined by the age composition and the vital rates of the immigrants. Thus the observed age distribution of the immigrants entering in any given year gives rise to a limiting total of 1.38 million immigrants as against 1.24 million when the model age composition is assumed. The sizes of the native-born population are also different for the same reason.

If the annual number of immigrants changes by a certain percentage while the age composition remains the same, only the first half of Table 1 will be affected. However, their new values can be easily obtained by multiplying the present values with the ratio of the new to the current value of immigration.

The observed and the model age distributions, their limiting forms; and a few other characteristics for the total and the immigrant population may be seen in Table 2.

TABLE 2. LIMITING FORMS OF ACTUAL AND MODEL AGE DISTRIBUTION OF IMMIGRANTS, NATIVE-BORN AND TOTAL POPULATION AND MEASURES OF MORTALITY DERIVED FROM A GIVEN AND A MODEL AGE DISTRIBUTION OF 30,000 ANNUAL IMMIGRANTS

\begin{tabular}{|c|c|c|c|c|c|c|c|c|}
\hline $\begin{array}{c}\text { ACE } \\
\text { GROPP }\end{array}$ & $\begin{array}{c}\text { ANMUAL } \\
\text { NO.OF } \\
\text { MOMGRANTS }\end{array}$ & $\begin{array}{l}\text { STATYONARY } \\
\text { POPULATION }\end{array}$ & $\begin{array}{c}\text { ACE } \\
\text { SPECTFL } \\
\text { BIRTH } \\
\text { RATE }\end{array}$ & $\begin{array}{l}\text { PFRCENTAGE } \\
\text { DHSTRIBUTIONOF } \\
\text { NATIVEROFULATION }\end{array}$ & $\begin{array}{l}\text { DMMKGRNTS } \\
\text { POR G }\end{array}$ & $\begin{array}{l}\text { LIMITING AGE } \\
\text { TOTAL } \\
\text { POPULATTON } \\
\text { WEN }\end{array}$ & $\begin{array}{l}\text { IMMGGRANTS } \\
\text { FOR M }\end{array}$ & $\begin{array}{l}\text { Of } \\
\text { TOTAL } \\
\text { POPULATION }\end{array}$ \\
\hline $\begin{array}{c}0 \\
1-4 \\
5-9 \\
10-14 \\
15-19 \\
20-24 \\
25-29 \\
30-34 \\
35-39 \\
40-44 \\
45-49 \\
50-54 \\
55-59 \\
60-64 \\
65-69 \\
70-74 \\
75-79 \\
80-84 \\
85-89 \\
90+\end{array}$ & $\begin{array}{r}415 \\
719 \\
590 \\
1308 \\
3845 \\
6369 \\
3657 \\
1464 \\
272 \\
295 \\
1001 \\
1960 \\
2541 \\
2268 \\
1282 \\
926 \\
588 \\
336 \\
139 \\
25\end{array}$ & $\begin{array}{r}99361 \\
396652 \\
495217 \\
494759 \\
494043 \\
493041 \\
492009 \\
490737 \\
488998 \\
486204 \\
481704 \\
474458 \\
463244 \\
446408 \\
420946 \\
383372 \\
329230 \\
255222 \\
166009 \\
104369\end{array}$ & $\begin{array}{r}0 \\
0 \\
0 \\
0 \\
23 \\
85 \\
125 \\
74 \\
21 \\
3 \\
0 \\
0 \\
0 \\
0 \\
0 \\
0 \\
0 \\
0 \\
0 \\
0\end{array}$ & $\begin{array}{l}1.25 \\
4.99 \\
6.22 \\
6.22 \\
6.21 \\
6.20 \\
6.18 \\
6.17 \\
6.15 \\
6.11 \\
6.05 \\
5.96 \\
5.82 \\
5.61 \\
5.29 \\
4.82 \\
4.14 \\
3.21 \\
2.09 \\
1.31\end{array}$ & $\begin{array}{l}0.03 \\
0.26 \\
0.54 \\
0.87 \\
1.78 \\
3.90 \\
5.66 \\
6.43 \\
6.66 \\
6.68 \\
6.87 \\
7.33 \\
8.01 \\
8.59 \\
8.67 \\
8.26 \\
7.34 \\
5.82 \\
3.85 \\
2.44\end{array}$ & $\begin{array}{l}0.96 \\
3.87 \\
4.88 \\
4.96 \\
5.16 \\
5.66 \\
6.06 \\
6.23 \\
6.27 \\
6.25 \\
6.25 \\
6.29 \\
6.34 \\
6.31 \\
6.09 \\
5.63 \\
4.89 \\
3.83 \\
2.50 \\
1.58\end{array}$ & $\begin{array}{l}0.02 \\
0.36 \\
1.13 \\
1.88 \\
2.63 \\
3.38 \\
4.12 \\
4.85 \\
5.58 \\
6.29 \\
6.96 \\
7.58 \\
8.10 \\
8.49 \\
8.64 \\
8.45 \\
7.76 \\
6.40 \\
4.41 \\
2.97\end{array}$ & $\begin{array}{l}0.90 \\
3.68 \\
4.78 \\
4.99 \\
5.20 \\
5.40 \\
5.60 \\
5.80 \\
5.99 \\
6.16 \\
6.31 \\
6.42 \\
6.47 \\
6.43 \\
6.24 \\
5.85 \\
5.16 \\
4.11 \\
2.74 \\
1.78\end{array}$ \\
\hline TOTAL & 30000 & 7955982 & 1657 & 100 & 100 & 100 & 100 & 100 \\
\hline
\end{tabular}


The unusual shape of the limiting age distribution as revealed earlier in Figure 2 may now be seen in terms of the percentages by age groups. The age-specific birth rates and the stationary population, on which most of the calculations are based, are also shown in this table. The model age distribution of the immigrants is proportional to the stationary population and has not been separately shown.

\section{Additional Results Derived by Simulation}

The values of the principal demographic parameters for different values of total fertility rates are presented to demonstrate how the former are affected by the latter. These may be seen in Table 3, which also provides another example by assuming different total fertility rates for the nativeborn population and the immigrants.

TABLE 3. LIMITING SIZE OF POPULATION AND VALUES OF A FEW DEMOGRAPHIC CHARACTERISTICS ASSUMING DIFFERENT COMBINATIONS OF TOTAL FERTILITY RATES AND ANNUAL IMMIGRATION OF 30,000 PERSONS

\begin{tabular}{|c|c|c|c|c|c|c|}
\hline \multirow{3}{*}{ PARAMETERS } & \multicolumn{5}{|c|}{ TOTAL FERTILITY RATE OF NATIVES } & \multirow[t]{2}{*}{1,6} \\
\hline & \multicolumn{5}{|c|}{ TOTAL FERTILITY RATE OF MMMGRANTS } & \\
\hline & 1.4 & 1.6 & 1.8 & 1.6 & 1.8 & 1.8 \\
\hline $\begin{array}{c}R \\
B(I) \\
b(I) \\
B(N) \\
P(N) \\
b(N) \\
P \\
B \\
b \\
d(N) \\
d \cdot \\
r(I) \\
r(N) \\
r(P) \\
i \\
r\end{array}$ & $\begin{array}{r}0.6695 \\
10285 \\
0.0074 \\
13850 \\
1923295 \\
0.0072 \\
3307437 \\
24135 \\
0.0073 \\
0.0125 \\
0.0164 \\
-0.0142 \\
-0.0053 \\
-0.0091 \\
0.0091 \\
-0.0146\end{array}$ & $\begin{array}{r}0.7652 \\
11754 \\
0.0085 \\
15828 \\
2197981 \\
0.0072 \\
3582123 \\
27582 \\
0.0077 \\
0.0125 \\
0.0161 \\
-0.0132 \\
-0.0053 \\
-0.0084 \\
0.0084 \\
-0.0098\end{array}$ & $\begin{array}{r}0.8608 \\
13223 \\
0.0096 \\
17806 \\
2472696 \\
0.0072 \\
3856838 \\
31029 \\
0.0080 \\
0.0125 \\
0.0158 \\
-0.0121 \\
-0.0053 \\
-0.0078 \\
0.0078 \\
-0.0055\end{array}$ & $\begin{array}{r}0.7652 \\
11754 \\
0.0085 \\
23809 \\
2834040 \\
0.0084 \\
4218182 \\
35563 \\
0.0084 \\
0.0125 \\
0.0155 \\
-0.0132 \\
-0.0041 \\
-0.0071 \\
0.0071 \\
-0.0098\end{array}$ & $\begin{array}{r}0.8608 \\
13223 \\
0.0096 \\
26785 \\
3188252 \\
0.0084 \\
4572394 \\
40008 \\
0.0087 \\
0.0125 \\
0.0153 \\
-0.0121 \\
-0.0041 \\
-0.0066 \\
0.0066 \\
-0.0055 \\
-\end{array}$ & $\begin{array}{r}0.8608 \\
13223 \\
0.0096 \\
43089 \\
4487526 \\
0.0096 \\
5871668 \\
56312 \\
0.0096 \\
0.0125 \\
0.0147 \\
-0.0121 \\
-0.0029 \\
-0.0051 \\
0.0051 \\
-0.0055\end{array}$ \\
\hline
\end{tabular}

"Values of $\theta(O), m, T, l, P(I))$ and $d(I)$ are the same as in Table 1.

It may be mentioned that the values of $R$ shown in this table are those of the immigrants. The same for the native-born population can be similarly derived. Also, the age-specific fertility rates needed for this exercise have 
been estimated from a three parameter model based on the total fertility rate, the mean and the modal age of reproduction. This model developed by Romaniuc (1973) for Canada's birth projection has been used successfully ever since.

Note that some of the parameters, namely, $e(0), m, T$ and $I$, are held constant for this simulation exercise.' The assumption of a constant number of immigrants with unchanging age-composition fixes the size of the immigrant population $P(I)$, which depends only on $I$ but not on $R$. This feature and the eventual stationary nature of the model make the parameters $d(I)$ and $d(N)$ independent not only of $I$ or $P(I)$, but also of $R$. However, due to differences in the relative sizes of the native-born population and the immigrant populations for different values of $R$, the overall death rate decreases with $R$. As can be expected, the birth rates $b(I), b(N)$ and $b$ increase with $R$, as do several other parameters. Some of them, such as $B(I), B(N)$, and $P(N)$, not only depend on $R$ but also vary directly with $I$ as long as all the other things remain the same.

The nonlinear nature of the increase in ultimate population size with $R$ is quite noticeable. The size in million increases from 3.0 to 3.9 to 5.4 to 9.0 as the Total Fertility Rate (TFR) shifts from 1.2 to 1.8 by a constant increment of 0.2 . The nonlinearity can be explained by the presence of $1-R$ in the denominator of the formulas for $B$ and therefore for $P N$, as may be seen from equations (20) and (23), respectively. Naturally, these functions become more sensitive in the vicinity of $R$ equal to 1 , which is the case for a TFR of two children.

The results of an arithmetic exercise in which the immigrants and the native-born population are assumed to have different levels of fertility are shown in the last column of Table 3. As explained earlier, the procedure for obtaining the parameters under these altered conditions is quite simple and straightforward.

\section{Effect of Emigration}

The results presented so far are based on the assumption of a fixed number of immigrants and zero emigration. In the presence of emigration, as is certainly the case in Canada, minor changes in the computational steps, accomplished through a simple adjustment in the net reproduction rate $R$ and the expectation of life $e(0)$, are needed to produce the estimates of the desired parameters (Mitra, 1989). In Canada, a constant emigration rate of approximately 0.003 for all ages is assumed for projection and other purposes at this time. Accordingly, the computation of the parameters on the basis of that value of the emigration rate is made. 
Thus, corresponding to the values of $R=0.7923$ and $\mathrm{e}(0)=79.69$ (see Table 1), $\mathrm{R}^{*}=0.7309$ and $e^{*}(0)=70.71$ and, thereafter, the values of the other relevant parameters which may be seen in Table 4.

TABLE 4. DEMOGRAPHIC PARAMETERS OF THE LIMITING POPLLATION ASSUMING AN ANNUAL IMMIGRATION OF 30,000 AND RATES OF EMIGRATION AS 0 AND 0.003

\begin{tabular}{|c|c|c|}
\hline \multirow[t]{2}{*}{ PARAMEIERS } & \multicolumn{2}{|c|}{ EMIGRATION RATES } \\
\hline & 2 & 003 \\
\hline $\begin{array}{l}\text { Total Immigrant Population } \\
\text { Births to Immigrants } B(I) \\
\text { Total Births } B \\
\text { Births to Natives } B(N) \\
\text { Native Population } P(N) \\
\text { Total Population } P \\
\text { Deaths to Immigrants } D(I)=I \\
\text { Deaths to Natives } D(N)=B \\
\text { Total Deaths } D=B+I\end{array}$ & $\begin{array}{r}1384134 \\
11667 \\
56172 \\
44505 \\
4476328 \\
5860462 \\
30000 \\
56172 \\
86172\end{array}$ & $\begin{array}{r}1384134 \\
11667 \\
43356 \\
31689 \\
3065702 \\
4449837 \\
30000 \\
43356 \\
73356\end{array}$ \\
\hline $\begin{array}{l}\text { Birth Rate of Immigrants } b(I)=B(I) / P(I) \\
\text { Birth Rate of Natives } b(N)=B(N) / P(N) \\
\text { Birth Rate of Total Population } b=B / P \\
\text { Death Rate of Immigrants } d(I)=D(I) / P(I) \\
\text { Death Rate of Natives } d(N)=D(N) / P(N) \\
\text { Death Rate to Total Population } d=D / P \\
\text { Rate of Growth of Immigrants } r(I)=b(I)-d(I) \\
\text { Rate of Growth of Natives } r(N)=b(N)-d(N) \\
\text { Rate of Growth of Total Population } r=b-d \\
\text { Immigration Rate } i=I / P\end{array}$ & $\begin{array}{l}.0084 \\
.0099 \\
.0096 \\
.0217 \\
.0125 \\
.0147 \\
.0132 \\
-.0026 \\
-.0051 \\
-.0051\end{array}$ & $\begin{array}{l}.0084 \\
.0103 \\
.0097 \\
.0217 \\
.0141 \\
.0165 \\
-.0132 \\
-.0038 \\
-.0068 \\
-.0068\end{array}$ \\
\hline
\end{tabular}

*Values of $e(O), T F R, R, T$, etc. are the same as in Table 1.

It is somewhat surprising that an emigration rate of the magnitude of 0.003 can be the cause of such a significant decline in the two crucial population parameters, namely $R$ and $e(0)$. The decline in the net reproduction rate is a little less than $8 \%$, while it is over $11 \%$ for the life expectancy. For the sake of clarity, it should be mentioned that these changes in the parametric values should not be looked upon as a real decline in fertility and a rise in the level of mortality. In fact, the decline in the net reproduction rate measures the proportion of female babies that will be born in other countries to a cohort of women born in Canada. In the same way, the decline in the life expectancy measures the length of time a woman born in Canada can expect to spend elsewhere during her lifetime. The size of the stationary population is similarly reduced in the process, together with several other demographic parameters. These may be seen in Table 4, 


\section{S. Mitra}

which reproduces the values from Table 1 (based on absence of emigration) to facilitate comparison between the two examples.

\section{Descendants of the Immigrants}

It should be noted that the fertile segment of the population reaches its limiting size about 50 years after the start of the process (see equation 2). Similarly, the number of births to the first generation immigrants must also reach its limiting value $B(I)$ at the same time. In the same way, it can be shown that about the same number of years thereafter, the births to the second generation immigrants will attain their limiting value.

$$
B_{2}(I)=B(I) R
$$

Continuing in the same manner, one can write

$$
B_{3}(I)=B_{2}(I) R=B(I) R^{2}
$$

and so on. The sum total of all of these births to the different generations turns out to be

$$
B(I)+B_{2}(I)+B_{3}(I)+\ldots=B(I)\left(1+R+R^{2}+\ldots\right)=\frac{B(I)}{1-R}
$$

Notice that (35) is the same as the limiting value of the total number of births $B$ for the country as a whole. This is what one whould expect to find because the original native-born population will eventually become extinct since $R<1$, and the country will be populated only by the immigrants and their descendants.

Over the short run of say 150 years, the number of births to immigrants and their descendants should be at least $B(I)\left(1+R+R^{2}\right)$ because the births to immigrants will reach the limiting values for the first three generations, but by that time there will be higher generation women in the reproductive ages as well. In fact, for the lowest age of reproduction as 15 years, it is possible for even the tenth generation immigrants to become mothers at that time. However, the first three generations alone will account for a proportion given by (see formula 35 )

$$
\frac{B(I)\left(1+R+R^{2}\right)}{B}=(1-R)\left(1+R+R^{2}\right)=1-R^{3}
$$

of the limiting value of the total number of births. In Canada, that proportion turns out to be over $60 \%$ for the given $R^{*}$ value of 0.73 . As mentioned before, it is less than the value that would be obtained when the numerator of (36) is replaced by births to immigrants of all generations 
150 years after the start of the process. As a matter of fact, such an estimate can be made by using the length of a generation estimated by the average age of motherhood $T$. For a $T$ of 27.4, the total number of births after 150 years will then be given by those of 5.5 generations. Accordingly, the proportion - the lower limit of which was estimated by $1-R^{3}$ in (37) actually lies somewhere between $1-R^{5}$ and $1-R^{6}$ or between 79 and $85 \%$ respectively.

\section{Time to Reach the Stationary State}

For the population under study, the time to reach the stationary state will also be the time for the original population - the one present at the start of the process - to become extinct. This is so because, by then, only the immigrants and their descendants will comprise the resident population of the country. To study this process, one begins with an analysis of what has just been examined. That is, in 150 years the proportion of births to immigrants and their descendants in Canada will be more than $80 \%$ of the total births. The speed of the process of extinction of Canada's population at the beginning of the process can be better understood by looking at the trend of this proportion, which will assume a value of $95 \%$ in about 250 years. The limiting value of $100 \%$ can of course only be reached at infinity, but a practical definition of extinction may be set at a somewhat lower level such as $95 \%$ or any other acceptable figure from which the time to reach the stationary state can easily be estimated.

\section{Overview and a Brief Summary}

Peacetime fertility decline in most of the developed nations is one of the several visible manifestations of human adaptation to social change. At the micro-level, the recent decline in fertility seems more like an individual response to the standards set by the social institutions as well as by life's aims and aspirations. The new values and norms, quite often at odds with the prevailing ones, seem to be gaining ground and setting the trend for the future.

The upward spiralling costs of bearing and rearing children have turned parenthood into a liability rather than an asset, and it is a small wonder that the cross-sectional reproductive index, like the total fertility rate, has fallen so far below the level of replacement. There is hardly a pronatalist measure that can turn things around and prevent the eventual decline in population growth caused by the continuation of the current reproductive behaviour of the Canadian population. The problem is worsened by the compounding effect of a substantial number of emigrants who are leaving Canada to try their luck elsewhere. 


\section{S. Mitra}

The macro-level response to counter such an outcome by allowing a steady flow of immigrants is timely and seems to be in the right direction. As has been seen (Table 4), an indefinite continuation of the current levels of mortality and fertility, an emigration rate of 0.003 at all ages, and an annual immigration of 30,000 women with the same age composition (Table 2); will produce a stationary state with a population of 4.45 million. The limiting size of the population, as has also been seen, is directly proportional to the volume of immigration when all other things remain the same. Thus, a threefold increase in the volume of immigration $(90,000)$ will result in a stationary population of 13.3 million. Remembering that this model is based on the female sex alone, necessary adjustments must be made for the male counterpart of the population at this stage. For reasons of simplicity, it is assumed that under normal conditions, doubling both of these numbers would serve the purpose reasonably well. That is to say, an annual immigration of about 180,000 persons will be required in order to reach a stationary state with a population of nearly 26 million, which is similar in size to Canada's present population.

Several alternative scenarios calling for appropriate modifications in the general analytic procedure have also been outlined in this paper. Thus, the immigrants may or may not adopt the net maternity rates of the host population, and there may or may not be any emigration of the native-born population. In any event, eventual stability is assured whenever the nativeborn population exhibit a below replacement status due to specific combinations of net maternity and emigration rates.

\section{Acknowledgments}

This study was made possible by a contract from Her Majesty the Queen in right of Canada. I am extremely grateful for the opportunity to work on this project, and in that endeavor, I sincerely appreciate the generous assistance provided to me by A. Romaniuc, Director, and M.V. George, Associate Director of the Demography Division of Statistics Canada. I am specially indebted to G. Cartier, M. Charbonneau, R. Costa, A. Gauthier, V. Kawka, D. Larrivee and J. Perreault for providing logistic and technical support without which this report could not have been written. I must add that the views expressed in this paper are solely mine and should not, in any way be interpreted as those of Her Majesty's Government. Finally, I am grateful for the suggestions of the anonymous reviewers in improving the presentation of this paper. 


\section{References}

Basavarajappa, K.G. and M.V. George. 1981. The future growth and structure of Canada's population: Results and implications of some demographic simulations. In Demographic Trends and Their Impact on the Canadian Labour Market. Catalogue no. 8-4200-501. Ottawa, ON: Statistics Canada and Employment and Immigration Canada.

Basavarajappa, K.G., R.B.P. Verma and C. Picton. 1984. Recent immigration trènds and its demographic implications. Paper presented at the annual meetings of the Canadian Population Society, Guelph, ON, Canada, June 9-11, 1984.

Espenshade, T.J., L.F. Bouvier and W.B. Arthur. 1982. Immigration and the stable population. Demography 19:125-133.

Mitra, S. 1983. Generalization of the immigration and the stable population model. Demography 20:111-115.

Mitra, S. and P. Cerone. 1986. Migration and stability. Genus 42:1-12.

Employment and Immigration Canada, Recruitment and Selection Branch, Immigration Division. 1983. The role of immigration in determining Canada's eventual population size.

Romaniuc, A. 1973. Three parameter model for birth projection. Population Studies 27:467478.

Received July, 1989; revised October, 1991.

\section{Appendix}

When mortality is the only cause of attrition, the age curve $\ell(x)$ of a birth cohort can be obtained from the differential equation.

$$
-\frac{1}{\ell(x)} \frac{d \ell(x)}{d x}=\mu(x)
$$

where $\mu(x)$ is the force of mortality at age $x$. If the same cohort were to experience another cause of attrition due to emigration, besides the force of mortality $\mu(x)$, the age curve would be

$$
-\frac{1}{\ell^{*}(x)} \frac{d \ell *(x)}{d x}=\mu(x)+o(x)
$$

where $o(x)$, like $\mu(x)$ is the instantaneous measure of outward movement. Noting that (A.1) and (A.2) can be alternatively expressed as

$$
\begin{gathered}
\ell(x)=e^{-\int_{0}^{x_{\mu}(y) d y}} \\
\ell^{*}(x)=e^{-\int_{0}^{x}(\mu(y)+0(y)) d y}
\end{gathered}
$$

respectively, we can write $\ell^{*}(x)$ in terms of $\ell(x)$ as

$$
\ell(x)=\ell(x) e^{-\int_{0}^{x_{0}(y) d y}}
$$


When the measure of outward migration $o(x)$ can be regarded as constant at all ages, say, $o(x)=k$, we get

$$
\ell^{*}(x)=e^{-\mathrm{kx} \ell(x)}
$$

Constant emigration rates at all ages given by $k=0.002$ or 0.003 are typically assumed for Canada. Next, the average number of years that a person can expect to live in the country of birth is given by

$$
e^{*}(0)=\int_{0}^{\alpha} e^{-\mathrm{kx} \ell}(x) d x
$$

For small $\mathrm{k}$, the approximation of this integral equation as

$$
e^{*}(0) \simeq e^{-\mathrm{km}} e(0)
$$

is quite good where $m$ is the average age of the stationary population and $e(0)$ is the expectation of life at birth. Using the Cranadian example of $e(0)=79.7$ and $m=41.3$ and $k=0.003$, we get $e(0)=70.7$ which is smaller than the simple expectation of life at birth by more than nine years.

Similarly, the net reproduction rate

$$
R=\int_{0}^{\alpha} \ell(x) m(x) d x
$$

and the average age of motherhood

$$
T=\int_{0}^{\alpha} x \ell(x) m(x) d x / R
$$

have their counterparts

$$
R^{*}=\int_{0}^{\alpha} e^{-\mathrm{kx}} \ell(x) m(x) d x
$$

and

$$
T^{*}=\int_{0}^{\alpha} x e^{-\mathrm{kx}} \ell(x) m(x) d x / R^{*}
$$

in the presence of emigration. As before, it can be easily shown that for small $k$

and

$$
R^{*}=R e^{-\mathrm{kT}}
$$

$$
T^{*}=T
$$

For $k=0.003, T=27.4$ and $R=0.7923$, we get a value of 0.7309 for $R^{*}$. 